\title{
Cut Throat Injury: A Tertiary Care Centre Experience
}

https://doi.org/10.47210/bjohns.2021.v29i1.381

Devang Gupta, ${ }^{1}$ Chaitry Shah, ${ }^{1}$ Vaishali Jain, ${ }^{1}$ Nikita Ganvit ${ }^{1}$

Introduction

\section{$\underline{\text { ABSTRACT }}$}

Cut throat injuries are one of the challenging emergencies encountered in clinical practice. This study evaluates the causes and management of cut throat injuries.

\section{Materials and Methods}

This was a retrospective study of total 100 cases of cut throat injury presented to the department of ENT in a tertiary care hospital in Ahmedabad between June 2017 and June 2019. Majority of patients were managed by suturing.

$\underline{\text { Results }}$

In our study $69 \%$ were males, $31 \%$ were females. The peak age of incidence is 4 th decade (55\%). $70 \%$ of them have injury in Zone II. Seventy eight percent of the patients presented with active bleed without major vessel injury. The most common cause of cut throat injury had been found to be accidental (75\%), 54\% had injury up to muscular layer. Five patients were managed by laryngotracheal stent placement.

Conclusion

The middle aged males were mostly affected. The majority had zone 2 injury. The most common cause was Accidental (seasonal manja/ kite thread cut). Primary repair is the best way to avoid complications.

Kevwords

Neck Injuries; Cut Throat; Kite Thread; Manja cut; Stent, Laryngotracheal

$\mathrm{C}$ ut-throat injuries form a major group in the casualties, especially in tertiary care set up. Cut throat injuries can be a life threatening. Profuse hemorrhage, shock, embolism due to major vessels or asphyxia resulting from aspirated blood are common cause of death and may lead to permanent sequalae, decreasing quality of life. Prevention of these untoward sequalae can be established either via endotracheal intubation or by tracheostomy and then surgical repair of transected tissues along with prompt control of hemorrhagic blood loss and blood replacement. The management of these injuries demands a multidisciplinary approach. As Otorhinolaryngologists, our aim should

1 - Department of Otorhinolaryngology, B.J.Medical

College and Civil Hospital,Ahmedabad

\section{Corresponding author:}

Dr Chaitry Shah

email: drchaitryent@yahoo.com be towards restoration of swallowing, phonation and breathing functions. Psychiatric consultation will be needed to rule out underlying mental illness in case of suicidal attempts.

The etiology of cut throat injuries are divided into three main groups: suicidal, homicidal and accidental. Accidental factors are mostly related to the road traffic accident and fall injuries. Apart from these, one of most common for accidental cut throat injuries in Gujarat, India is 'MANJA (kite thread) CUT INJURY', that occurs during regional festival famed as Uttarayan where people fly kites as a symbol of celebration and get accidently injured with strings of flying kites.

A sudden increase in number of admissions of patients with cut throat injuries prompted us to analyse this problem. The present study was done to assess the socio-demographic profile of patients of cut throat injury treated in our institute and triggering factors behind such injuries, anatomical structures injured by the cut throat 


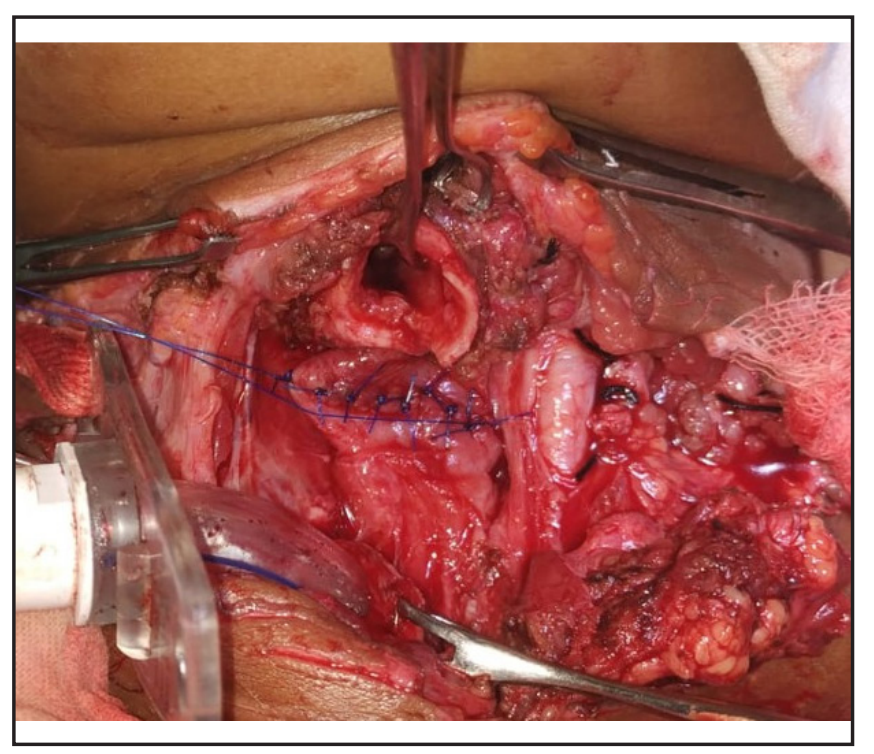

Fig. 1. Tracheo-oesophageal repair after cut throat

injury, treatment protocol of cut throat injury patients followed in our hospital and its results and complications encountered in the patients treated while understanding different sequalae of injury and ways to prevent it to improve the quality of life.

\section{Materials and Methods}

This was a retrospective study of total 100 cases of cut throat injury presented to us directly or referred from various primary and secondary health care units, to the department of ENT in Civil Hospital Ahmedabad between June 2017 and June 2019.

They were analysed for details of age, sex, aetiology, types of injury, anatomical zone of injury, surgical procedures and their complications. The evaluation of a cut throat injury starts on the basis of ATLS (Advanced Trauma Life Support) guidelines of A B C D E (Airway, Breathing, Circulation, Disability and Exposure). After stabilization of the patient, a complete history is taken and thorough physical examination is done. Blood transfusion with whole blood was carried out in patients who had severe bleeding and those were brought in the state of shock. Suction clearance of the secretions and blood from the wound was done to prevent aspiration. The debridement and repair of wound with or without

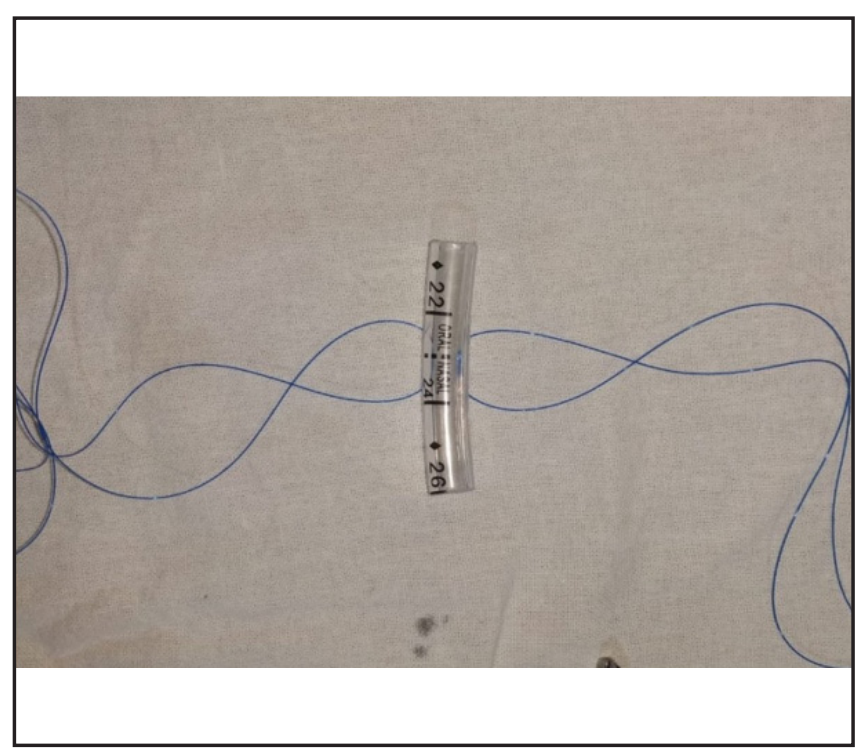

Fig. 2. Stent made up of Endotracheal tube

tracheostomy was done depending on the severity of injury. (Fig. 1)

Injuries of neck are divided into three anatomical zones according to Roon and Christensen's classification: 1) Zone I injuries occur at the thoracic outlet, which extends from the level of the cricoid cartilage to the clavicles.

2) Zone II is superior to zone I injuries occur in the area between the cricoid and the angle of the mandible. Injuries here are the easiest to expose and evaluate.

3) Zone III injuries are between the angle of the mandible and the base of the skull. Although zones I and III are protected by bones and the vital structures in the zone II are not protected by bone, so the risk of injury is different in three zones.

Evaluation of extent of injury starts with assessment of vocal cord mobility and anatomy of laryngeal framework, arytenoid fixation and oesophagus. Exploration under GA/LA is done depending upon severity of injury. After thorough wash, wound was explored and bleeding points were ligated or coagulated by electrocautery. In patients with involvement of thyroid cartilage, and other laryngeal cartilages, repair was done approximating the

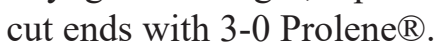

In cases of transected trachea, it was sutured 


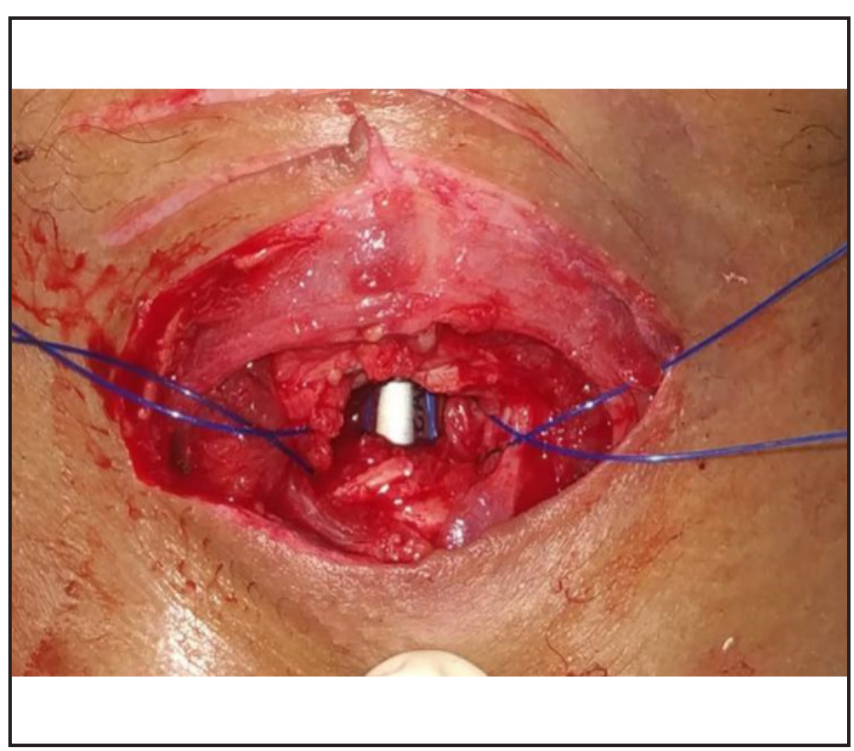

Fig. 3. Laryngotracheal reconstruction using stent

circumferentially with interrupted 3-0 Prolene $\AA$. when part of tracheal cartilage was lost completely or irrepairable, resection and end-to-end anastomosis to be done, however not done in our study. In apt cases where one or more cuts were present over larynx and trachea, we used stent made up of endotracheal tube (Fig. 2) which was placed just above tracheostomy tube and secured in the neck. (Fig. 3)

Absorbable sutures were used to suture the fascia, muscles and soft tissue of the neck. Skin was closed in two layers by 3-0 Vicryl ${ }^{\circledR}$ for subcutaneous tissue and 3-0 Ethilon ${ }^{\circledR}$ for epidermis. RT was inserted in all patient of laryngeal and tracheal injury to prevent tracheo-oesophageal fistula and provide rest to injured trachea.

Regular dressings were done. Suture removal was done after 10 days. Follow up for 3 months was done along with endoscopic evaluation of airway. Psychiatrist consultation was taken in needed cases. Average hospital stay was less than 2 weeks.

\section{Result}

Among 100 patients there were 69 male and 31 female. Majority of the patients $(70 \%)$ had injury in zone II while 22 patients $(22 \%)$ in zone I; and 8 patients $(8 \%)$ had zone III neck injury. (Table I)

Among all causative factors, accidental and that too because of injury while kite flying were attended in majority (38\%)patient. 18\% patients were found to be victim of homicidal factors. Minority $7 \%$ were presented with self injured causes. (Table II)

Majority of patients (54\%) presented with injury upto muscular layer with platysma and sternocleidomastoid muscles being common muscles to get severed. $28 \%$ patients presented only with superficial injury involving skin and subcutaneous tissue layer. Trachea was exposed and injured in $5 \%$ patients who also had difficulty in breathing. $1 \%$ patients were having oesophegeal injury. $10 \%$ patients were having active uncontrolled bleeding due to injury to major vessels including carotid artery and jugular veins. (Table III)

Intubation was done first in patients with breathing difficulty who didn't have any laryngeal and tracheal injury. While with compromised airway tract, patients were directly tracheostomised and thereby airway was secured. After maintenance of $100 \%$ oxygen saturation on air with normal vocal cord mobility, they were given temporary tracheostomy closure followed by permanent closure.

In 5 patients, we placed laryngeal and tracheal stent under endoscopic guidance for stability and to prevent collapse following laryngotracheal reconstruction. We recommend stent removal between 3-6 months after insertion, with regular monthly follow up.

In 2 patients stent removal was done after 6 months and airway was normal. In our study one patient developed obstructive granulation tissue at the end of the stent after 3 months requiring further treatment with LASER excision or Tracheostomy. Stent dislodgement

Table I: Distribution of patients according to anatomical zone of injury

\begin{tabular}{|c|c|c|}
\hline $\begin{array}{c}\text { ANATOMICAL } \\
\text { ZONE }\end{array}$ & $\begin{array}{c}\text { NO. OF } \\
\text { PATIENTS }\end{array}$ & $\begin{array}{c}\text { PERCENTAGE } \\
(\%)\end{array}$ \\
\hline Zone-I & 22 & 22 \\
\hline Zone-II & 70 & 70 \\
\hline Zone-III & $\mathbf{8}$ & 8 \\
\hline
\end{tabular}


Table II: Distribution of patients according to mode of injury

\begin{tabular}{|c|c|c|c|}
\hline MODE OF INJURY & FACTOR & NO. OF PATIENTS & PERCENTAGE (\%) \\
\hline \multirow{3}{*}{ Accidental } & Kite flying Road & 38 & 38 \\
\hline & Road traffic accident & 21 & 21 \\
\hline & Fall from height & 16 & 16 \\
\hline \multirow{2}{*}{ Homicidal } & Robbery & 10 & 10 \\
\hline & Land dispute & 8 & 8 \\
\hline \multirow{3}{*}{ Suicidal } & $\begin{array}{l}\text { Low socio-economic } \\
\text { condition }\end{array}$ & 3 & 3 \\
\hline & Substance abuse & 2 & 2 \\
\hline & Family abuse & 2 & 2 \\
\hline
\end{tabular}

occurred shortly after the procedure in 1 patient which was treated with new stent insertion. 1 patient was lost during follow up.

Major complication we found was Secondary wound infection and scar in 5\% patients. Tracheo-esophageal fistula was seen in only $1 \%$ patients. $2 \%$ presented with difficulty in phonation having (vocal cord paralysis). $2 \%$ patients came with difficulty in breathing due to Laryngo-tracheal stenosis which were further treated with stenting or T-tube insertion later on. Subcutaneous emphysema seen in 5\% due to apical lung injury. (Table IV)

\section{Discussion}

According to World Health Organization (WHO), worldwide mortality rate of cut throat injury is 5 million. It is estimated that for every death only $15 \%$ gets hospitalized and $80 \%-85 \%$ receives emergency care that demands improvement in urgent access to emergency medical care in our country. ${ }^{1}$

In this study, age incidence of the victims were 10 to 70 years. Most of the patients were males in their fourth decade of life belonging mainly to rural area which is similar to studies of Bhattacharjee et al., Panchappa et al. and Manilal et al., ${ }^{2,3}$ Male preponderance in this age group is due to their active participation in

Table III: Distribution of patients according to structure involved

\begin{tabular}{|c|c|c|}
\hline SITE OF WOUND & NO. OF PATIENTS & PERCENTAGE (\%) \\
\hline Skin and subcutaneous layer & 28 & 28 \\
\hline Muscular layer & 54 & 54 \\
\hline Injury to larynx and recurrent laryngeal nerve & 2 & 5 \\
\hline Tracheal injury & 5 & 10 \\
\hline Injury to major vessels of neck & 10 & 1 \\
\hline Injury to oesophagus & 1 & \\
\hline
\end{tabular}


Table IV: Distribution of patients according to complications

\begin{tabular}{|c|c|c|}
\hline POST OPERATIVE COMPLICATIONS & NO. OF PATIENTS & PERCENTAGE (\%) \\
\hline $\begin{array}{c}\text { Secondary wound infection and scar } \\
\text { Decannulation problems and permanent } \\
\text { tracheostomy }\end{array}$ & $\mathbf{1}$ & $\mathbf{5}$ \\
\hline Tracheo-esophageal fistula & 1 & 1 \\
\hline Laryngo-tracheo stenosis & 2 & 2 \\
\hline Neurological deficit (vocal cord paralysis) & 2 & 5 \\
\hline
\end{tabular}

risky behaviours and their frequent involvement in interpersonal conflicts. In our study we have noticed a sharp rise in incidence of cut throat injuries in the month of December and January because of regional kite flying festival (known as Uttarayan or Makarsankranti) which is celebrated widely across the entire Gujarat state similar as Panchappa et al. study. ${ }^{3}$ Psychiatric illness was the most frequent cause for suicidal attempts. Similar findings were found in study done by Gilyoma et al. ${ }^{5}$ In our study males out- numbered the females among the victims of suicidal cut throat injuries. Our result is similar to the study by Bhattacharya et al. ${ }^{2}$

Regarding the site of injury, majority of our patients had injury in zone II i.e. in the region between the cricoid cartilage and the angle of mandible as it is usually the most frequently involved (60-75\%) site in penetrating neck injuries. Zone II is not protected by bony structures thus making it prone for injuries more commonly than zone I and III, findings similar to studies of Manilal et al. and Parajuli et al., ${ }^{4,6}$ In our study the most commonly performed surgical procedures were primary repair of the wound, tracheostomy and laryngeal/ hypopharyngeal repair. Patients with injury to the hypopharynx, larynx and trachea underwent tracheotomy to protect airway. Similar results were reported by studies of Bhattacharjee and Gilyoma. ${ }^{2,5}$

Majority of patients in our study presented with open wounds and active bleeding, treatment outcome was better in those people who were given emergency treatment early (within 12 hours). We have noticed that as the treatment delays, the chance of wound infection and pharyngo-cutaneous fistula rises.

In our study total $5(5 \%)$ victims required tracheostomy and was lifesaving in them. Regarding treatment outcome some patients are living normal life after treatment, some patients are living with minor disability like change of voice and mild dysphagia. Worst complications seen were Laryngeal stenosis, pharyngeal stenosis and pharyngo-cutaneous fistula. In our study two patients had tracheal stenosis which were then managed with ' $T$ ' tube insertion. Also we had noted the usefulness of stent insertion (created by ET tube) as in all the patients of laryngeal injury in whom the stent was inserted, no stenosis seen and post-operative results were excellent. Pharyngo-cutaneous fistula can be effectively prevented by Ryle's tube feeding and avoiding oral feeds in the post-operative period. Patients with suicidal and homicidal injury were evaluated by psychiatrist. This is because the act of suicide is a sign of an underlying mental illness and there may be a possibility of a second attempt.

\section{Conclusion}

Accidental cut throat injuries have become a major cause of morbidity and mortality among young males in our society due to accidental cause and psychiatric illness caused by high rates of unemployment, poor socioeconomic status, poor education, poverty and substance abuse. Multidisciplinary approach required in the management of cut throat injury patients. The timely and correct management is essential for a successful 
clinicaloutcome. Preliminary tracheostomy needed in those patients presenting with injury involving the larynx or upper trachea. The patient's feeding are better managed with Ryle's tube in post operative period. Postoperative endoscopy identifies the nerve injuries and stenosis problems. It is important to record protocols used and correct operative findings for medico-legal purpose and future reviews.

Kite-flying and kite-string injuries can have severe consequences although kite flying cannot be banned in a country like India where it is seen as enjoyable leisure time, symbol of celebration and part of tradition. We can make common people aware of its sequel, through electronic media and also by information booklets and pamphlets and encourage people to wear hand gloves and cover the exposed parts while flying a kite. Morbidity and mortality among injured patients could be reduced by increasing the emergency health care services, ambulance system, first aid.

\section{References}

1. Krug EG, Sharma GK, Lozano R. The global burden of injuries. Am J Public Health 2000; 90:523-6. doi: 10.2105/ AJPH.90.4.523

2. Bhattacharjee N, Arefin SM, Mazumder SM, Khan MK. Cut throat injury: a retrospective study of 26 cases. Bangladesh Med Res Counc Bull. 1997; 23:87-90

3. Panchappa SA, Natarajan D, Karuppasamy T, Jeyabalan A, Ramamoorthy RK, Thirani S, Swamirao RK. Cut throat injuries - a retrospective study at a Tertiary Referral Hospital. Int J Otolaryngol Head Neck Surg. 2014; 3:323-9. doi: 10.4236/ ijohns.2014.36058

4. Manilal A, Khorshed ABM, Talukder DC, Sarder RMA, Fakir AT, Hossain M. Cut throat injury: review of 67 cases. Bangladesh J Otorhinolaryngol. 2011; 17:5-13

5. Gilyoma JM, Hauli KA, Chalya PL. Cut throat injuries at a university teaching hospital in northwestern Tanzania: a review of 98 cases. BMC Emerg Med. 2014; 14 (14):1. doi: 10.1186/1471-227X-14-1

6. Parajuli R, Limbu T, Bhandari R, Thapa S, Tulachan B. (2015). Management of Cut Throat Injury: A Review of 20 Cases. Journal of Universal College of Medical Sciences 2015; 3(3):36. https://doi.org/10.3126/jucms.v3i3.2 